\title{
HARMONIZAÇÃO OROFACIAL: A ODONTOLOGIA ALÉM DO SORRISO
}

Andrea Nóbrega Cavalcanti' ${ }^{1}$ Juliana Felippi Azevedo ${ }^{2}$, Paula Mathias ${ }^{3}$

\author{
Autora para correspondência: Andrea Nóbrega Cavalcanti - ancavalcanti@bahiana.edu.br \\ 'Doutora em Clínica Odontológica/Dentística. Professora na Escola Bahiana de Medicina e Saúde Pública \\ e na Universidade Federal da Bahia. Salvador, Bahia, Brasil. \\ ${ }^{2}$ Doutora em Dentística Restauradora. Professora na Escola Bahiana de Medicina e Saúde Pública. Salvador, Bahia, Brasil. \\ ${ }^{3}$ Doutora em Clínica Odontológica/Dentística. Professora na Universidade Federal da Bahia. Salvador, Bahia, Brasil.
}

Estética, Harmonização, Integração, Muldisciplinaridade. Palavras frequentemente associadas à Odontologia contemporânea. Escuta-se sobre elas em congressos das diversas especialidades, em notícias de jornais e revistas e cada vez mais em nossos consultórios. O peso destas ideias é inquestionável porque, de fato, representam um novo momento da Odontologia.

Difícil pensar em conceitos novos com olhos acostumados com regras do passado. Para entender a necessidade da harmonização orofacial é preciso observar e vivenciar o momento atual da sociedade. $O$ que querem nossos pacientes? Saúde, função, beleza, rejuvenescimento, harmonia e bem-estar. São pedidos que vão além do sorriso, e que para serem oferecidos, requerem que o profissional esteja atualizado com terapêuticas estéticas e cosméticas, seja para aplica-las ou para indica-las. A Odontologia é uma grande aliada, não apenas no restabelecimento da função e bem-estar, mas, principalmente, na busca por um sorriso em harmonia com uma face equilibrada, o que é definido como beleza e jovialidade.

Estudos demonstram que tratamentos modernos e cada vez mais promissores trazem possibilidades de atingir equilíbrio e simetria da face, resolver questões funcionais, como a dor e a disfunção mastigatória, amenizar o envelhecimento e oferecer qualidade de vida. Entre eles, pode-se reconhecer $\circ$ uso da toxina botulínica, dos preenchimentos e cirurgias para contornos faciais e da viscossuplementação da articulação temporomandibular (ATM) $)^{1-4}$.

A toxina botulínica é uma neurotoxina que bloqueia a condução do estímulo nervoso, diminuindo o potencial de contração muscular pela inibição da ação da acetilcolina. Em Odontologia, ela é utilizada de forma segura e bem tolerada em dores musculares crônicas, associada ou como alternativa a outras terapêuticas com resultados limitados ou que apresentam efeitos colaterais indesejados. A eficácia do bloqueio nervoso sobre a harmonização facial é inegável. Resultados estéticos satisfatórios são vistos em situações de diminuição do sorriso gengival e correção de assimetrias dos músculos associados ao sorrir. A combinação de dois fatores justifica o crescente estudo e emprego de tais procedimentos; são eles: o conhecimento aprofundado que o cirurgião dentista tem a 
respeito da anatomia facial, e a perspectiva atual de opção por técnicas minimamente invasivas ${ }^{1,4}$.

Os materiais de preenchimento orofacial têm diversas aplicações no ambiente oral e extra oral. São usados para aumentar o volume interdental, consequentemente reduzindo black spaces periodontais, para suavizar linhas de expressão, especialmente ao redor dos lábios e harmonizar a face como um todo. Porém, a evidenciação de contornos faciais também tem potencial para agregar beleza à face. As técnicas que promovem tal resultado, em geral, removem tecido adiposo de locais específicos e parecem apresentar efeitos satisfatórios ${ }^{3}$.

O uso do ácido hialurônico para manejar desordens da ATM vem se desenvolvendo em função dos promissores resultados desta viscossuplementação em lesões de articulações maiores, como joelhos. Atualmente, estudos clínicos vêm sendo conduzidos com objetivo de personalizar este tratamento baseando-se na identificação do paciente e no efeito desejado, já que as possibilidades de disfunções da ATM são inúmeras. Outra questão importante, ainda em discussão, é a definição do número ideal de sessões de infiltração necessárias para garantir efeitos positivos e duradouros. Reduzir o número de sessões tem implicações clínicas, biológicas e sociais; logo, este aspecto deve receber atenção das pesquisas nos próximos anos ${ }^{2}$.

Importante destacar que a Odontologia, em suas técnicas já consagradas e de uso rotineiro, já traziam grande impacto para a composição e harmonia faciais. São exemplos o aumento e reanatomização de dentes, promovidos por técnicas restauradoras, a alteração de perfil facial por movimentações ortodônticos ou por cirurgias bucomaxilofaciais, como as ortognáticas. Entretanto, esse movimento acontecia quase que exclusivamente de dentro para fora. O intra-oral modificando o extra-oral. Hoje, o olhar da profissão foi ampliado, se integrando com outras áreas da saúde e extendendo a ação da Odontologia. Assim, novos ângulos de observação estão disponíveis e são capazes de fornecer ainda mais ferramentas na valorlzação da estética facial. Vamos cada vez mais aprender a olhar a face, dando protagonismo ao sorriso, como ele merece, por ser uma das expressões mais dinâmicas e marcantes que o ser humano possui.

Relativamente novos, é compreensível que esses procedimentos tragam dúvidas e incertezas. A consciência da necessidade de domínio, estudo e apropriação do assunto são fundamentais para que essas técnicas sejam utilizadas em sua plenitude e tragam resultados confiáveis. A ciência está em constante movimento e a Odontologia deve seguir - mesmo curso. Ir além do sorriso não significa ir atrás de modismos; e, sim, ir no rumo da evidência, da comprovação da eficácia, da ética e do sucesso.

\section{REFERÊNCIAS}

1. Awan KH. The therapeutic usage of botulinum toxin (Botox) in non-cosmetic head and neck conditions - An evidence based review. Saudi Pharm J. 2017;25(1):18-24. doi: $10.1016 /$ i.jisps.2016.04.024

2. Guarda-Nardini L, Rossi A, Arboretti R, Bonnini S, Stellini E, Manfredini D. Single- or multiple-session viscosupplementation protocols for temporomandibular joint degenerative disorders: a randomized clinical trial. J Oral Rehabil. 2015;42(7):521-8. doi: 10.1111 /joor.12282

3. Pretel H, Cação I. Harmonização Orofacial: Toxina Botulínica, Preenchedores Orofaciais e Fototerapia. 1 a ed. São José dos Pinhais: Editora Plena; 2016. p. 188.

4. Srivastava S, Kharbanda S, Pal US, Shah V. Applications of botulinum toxin in dentistry: A comprehensive review. Natl J Maxillofac Surg. 2015;6(2):152-9. doi: 10.4103/0975$\underline{5950.183860}$ 